\title{
InterMiG: international differences in the therapeutic approach to migraine patients in specialized headache centers
}

\author{
AB Gago-Veiga 1*, J-I Huhn², N Latysheva ${ }^{3}$, A Vieira Campos ${ }^{1}$, M Torres-Ferrus ${ }^{4,5}$, A Alpuente Ruiz ${ }^{4,5}$, S Sacco ${ }^{6}$, \\ I Frattale ${ }^{6}$, R Ornello $^{6}$, R Ruscheweyh 7 , IB Marques ${ }^{8}$, A Gryglas-Dworak $^{9}$, C Stark ${ }^{10}$, VJ Gallardo ${ }^{4,5}$ and \\ P Pozo-Rosich ${ }^{4,5}$
}

\begin{abstract}
Background: There is currently a wide therapeutic arsenal for migraine patients, without a single first-line preventive drug and we choose the different available alternatives taking into account comorbidities, national guidelines, previous treatments and personal experiences.

Our objective was to evaluate the differences in the use of migraine treatments between neurologists from different countries.
\end{abstract}

Methods: This is a multi-centre observational study carried out by neurologists from specialized headache units in seven countries, retrospective with consecutive inclusion of all patients presenting with a migraine diagnosis, over a period of three months.

Results: A total of 734 patients were recruited but only 600 were considered in the analysis in order to homogenize the patient cohorts from countries: 200 Spain (ES), 100 Italy (IT), 85 Russia (RUS), 80 Germany (DE), 60 Portugal (PT), 45 Poland (PL) and 30 Australia (AU). $85.4 \%$ of patients were women with a mean age of $42.6 \pm 11.8$ years. Considering previous and current preventive treatment, the order of use was: antidepressants (69.3\%), antiepileptic drugs (54.7\%), beta-blockers and antihypertensive drugs (49.7\%), OnabotulinumtoxinA (44.0 \%) and others (36.2\%).

Statistically significant differences were found between all pharmacological classes: antidepressants were commonly used in all countries, with the exception of Poland (AU: 76.7\%, IT: 71.0\%, DE: 60.0 \%, PL: 31.1 \%, PT: $71.7 \%$, RUS: $70.6 \%$, ES: $78.5 \%$; $p<0.0001)$; antiepileptic drugs were more frequently prescribed in Portugal, Australia and Spain (AU: $73.3 \%$, IT: $40.0 \%$, DE: $37.5 \%$, PL: $48.9 \%$, PT: $85.0 \%$, RUS: $29.4 \%$ and ES: $69.0 \%$; $p<0.0001$ ); beta-blockers and antihypertensive drugs were frequently used in all countries except Italy (AU: $60.0 \%$, IT: 14.0\%, DE: $53.8 \%$, PL: 48.9\%, PT: $68.3 \%$, RUS: $49.4 \%$ and ES: $59.0 \%$; $p$ 0.0001); BTX-A were predominately used in Spain, Italy and Australia (AU:56.7\%, IT:58.0 \%, DE:20.0\%, PL: 42.2\%, PT: $26.7 \%$, RUS: $24.7 \%$ and ES: $58.5 \%$; $p<0.0001$ ) and others were most frequently used in Poland (AU: $0.0 \%$, IT: $19.0 \%$, DE: 42.5 \%, PL: $95.6 \%$, PT: $31.7 \%$, RUS: $3.5 \%$ and ES: $49.5 \% ; p<0.0001$ ). If only patients without comorbidities are considered (200/600), statistically differences between countries persist in all preventive treatments.

\footnotetext{
* Correspondence: dra.anagago@gmail.com

${ }^{1}$ Headache Unit, Department of Neurology, La Princesa Research Institute. Hospital Universitario de la Princesa, Madrid, Spain

Full list of author information is available at the end of the article
}

(c) The Author(s). 2021 Open Access This article is licensed under a Creative Commons Attribution 4.0 International License, which permits use, sharing, adaptation, distribution and reproduction in any medium or format, as long as you give appropriate credit to the original author(s) and the source, provide a link to the Creative Commons licence, and indicate if changes were made. The images or other third party material in this article are included in the article's Creative Commons licence, unless indicated otherwise in a credit line to the material. If material is not included in the article's Creative Commons licence and your intended use is not permitted by statutory regulation or exceeds the permitted use, you will need to obtain permission directly from the copyright holder. To view a copy of this licence, visit http://creativecommons.org/licenses/by/4.0/ The Creative Commons Public Domain Dedication waiver (http://creativecommons.org/publicdomain/zero/1.0/) applies to the data made available in this article, unless otherwise stated in a credit line to the data. 
Conclusions: There is heterogeneity in the choice of preventive treatment between different countries. Prospective comparative studies of the different oral and subcutaneous alternatives would help to create a global therapeutic algorithm that would guarantee the best option for our patients.

Keywords: Migraine, Preventive treatment, International, Differences, Antidepressant, Antiepileptic, Beta-blockers, OnabotulinumtoxinA

\section{Background}

Migraine is a chronic disease accounting for a large proportion of disability across all ages, especially in the young. In fact, in 2019 migraine was named the first was named the first disabler under the age of 50 [1].

It has been estimated that up to $38 \%$ of migraine patients need preventive treatment [2]. However, the international guidelines on migraine prophylaxis only contain a list of medications, which have undergone randomized clinical trials and show their level of evidence [3, 4]. These documents do not give recommendations on the choice of first-line drugs.

More recent guidelines have summed up the real-life experience of general practitioners and headache centers and recommend that the choice of a migraine prophylactic drug should be based on the attack frequency (episodic vs. chronic), comorbid diseases and the patient's individual needs [5, 6]. Differences in national healthcare systems and reimbursement policies also factor in the choice of preventive strategies in different countries.

This heterogeneity of treatment practices may also be partly explained by the differences in headache care systems. Whereas in some countries general practitioners successfully treat most patients with migraine, in others countries this is not the case, resulting in a large number of drug-naive patients referred to third-level headache centers. Such differences in patient populations and proportions of refractory headaches seen by specialized centers may also influence drug choice.

In consequence, the objective of this study was to evaluate the differences of preferences of use of acute and preventive migraine treatments internationally across headache centers in several countries.

\section{Methods}

\section{Study population}

We performed a multicentre retrospective observational study with consecutive inclusion of patients, carried out by neurologists from specialized headache units in seven countries: Spain (ES) (La Princesa University Hospital and Vall d'Hebron University Hospital), Germany (DE) (Praxis Gendolla and Ludwig Maximilians University Munich), Russia (RUS) (Sechenov University), Italy (IT) (University of L'Aquila), Portugal (PT) (Hospital da Luz
Lisboa), Poland (PL) (Private Headache Clinic Wroclaw) and Australia (AU) (Austin Health). Each centre was required to contribute at least 30 patients, starting data collection in February 2019 and continuing for a maximum of three months. The inclusion criteria were: patients with migraine diagnosed according to the International Classification of Headache Disorders-3 [7], who were 18 years of age, with no upper age limit. Patients were excluded when not enough data was collected in their medical history.

\section{Methodology of the study}

Each participating neurologist had to complete a data sheet, when they evaluated a patient with migraine (both first and follow-up visits could be included). The data to be collected were as follows: age, gender and referring physician. The baseline characteristics considered were: comorbidities - ischemic cardiac disease, hypertension, (pre) syncope, asthma, nephrolithiasis, gastritis, depression/anxiety, and body mass index (BMI). With respect to current acute treatment, the use of each of the triptans, paracetamol, non-steroidal anti-inflammatory drugs (NSAIDs,) metamizole, opiates and combined drugs was documented. We categorized preventive treatment into five different pharmacological categories, about current and previously used drugs, including: antiepileptic drugs (AEDs) (topiramate (TPM), valproic acid (VPA), pregabalin (PGB), zonisamide (ZNS) and lamotrigine (LMT)), antidepressants (amitriptyline (AMT), serotonin reuptake inhibitors (SSRI), serotonin and norepinephrine reuptake inhibitors (SNRI) (duloxetine, venlafaxine), vortioxetine, opipramol and agomelatine), beta-blockers (BB) and antihypertensive drugs (candesartan and lisinopril), onabotulinumtoxin A (BTX-A) and "others" (calcium Channel Blockers (CCB) (Flunarizine and Cinnarizine), anesthetic blocks, magnesium $(\mathrm{Mg})$ and riboflavin).

This study was approved by the Hospital de la Princesa's Ethics Committee (register number: 3477). Patient data were anonymized for data analysis.

\section{Statistical analyses}

We report nominal (categorical) variables as frequencies (percentages) and continuous variables as mean \pm standard deviation for normally distributed variables (age and 
basal headache frequency). We checked normality assumption of quantitative variables through visual methods (Q-Q plots). We assessed statistical significance of comparisons between countries by Pearson's chisquare test when comparing categorical variables and in the case of having an expected count less than 5 in more than $20 \%$ of cells in the contingency table, we used the Fisher's exact test. One-way ANOVA was used in order to study group mean differences between countries and patient's age and headache frequency.

We did not conduct a statistical power calculation prior to the study because the sample size was based on the available data. No missing values were obtained. No adjustment for multiple comparisons were made to the statistical inferences, but exact $P$ values were reported to allow post adjustments, if desired. $\mathrm{P}$ values presented are for a two-tailed test and we considered $\mathrm{P}$ values $<0.05$ statistically significant. All analysis was done using SPSS statistical package, v21.0 for Windows (IBM Corp. Released 2012. Armonk, NY: IBM Corp.)

\section{Results \\ Participants}

A total of 734 patients were included but there were statistically significant differences in age and gender between countries. In order to obtain a homogeneous population, we randomly selected age- and gendermatched patients considering the same age-range (2070 years old) and gender distribution with a similar equally proportional effect between countries. Patients who had not tried any preventive treatment $(8.4 \%$; 62/ 734) and pregnant patients (or those hoping to be) $(3.1 \% ; 23 / 734)$ were not included. Hence, the final sample size considered for the following analysis was 600 patients (30 AU, $100 \mathrm{IT}, 80 \mathrm{DE}, 45 \mathrm{PL}, 60 \mathrm{PT}, 85$ RUS and $200 \mathrm{ES}) .85 .4 \%(515 / 600)$ were females with a mean age of $42.6 \pm 11.8$ years. Mean headache frequency was $17.5 \pm 8.5$ days/month and $25.5 \%(154 / 600)$ of patients had migraines with aura. Chronic migraine $(\mathrm{CM})$ was observed in $63.5 \%(381 / 600)$ of patients. The median of current and previous preventives used by patient was 3.0. Regarding the main comorbidities that may influence the choice of a migraine preventive treatment, the most prevalent was mood disturbance (anxiety and/or depression), followed by, overweight (BMI $\geq 25)$, arterial hypertension, gastritis and asthma, in this order. Patients were principally referred by general practitioners and general neurologist. Main demographical data and distribution among countries are shown in Table 1, where significant differences can be seen.

\section{Use of migraine acute medication}

The most commonly used acute drugs were triptans, especially sumatriptan, followed by NSAIDs and, much less frequently, paracetamol, combined treatments metamizole and opioids (Table 2). Statistically significant differences between countries were found in the use of each acute treatment (Table 2). Triptans were more frequently used in Poland and Russia but in general by at least half of patients in all countries. The use of NSAIDs predominates in countries like Poland and Italy although their use is not as frequent in countries like Australia. In relation to the rest of analgesic medication, their use was drastically reduced compared to the previous two, except for paracetamol in Poland or Australia.

We set out to study if acute medication prescription in countries was influenced by patient diagnosis or the type of medical referral. For that reason, we only performed

Table 1 Demographics, migraine characteristics, main comorbidities and medical referral according to each country

\begin{tabular}{|c|c|c|c|c|c|c|c|c|c|}
\hline & $\begin{array}{c}\text { Australia } \\
(n=30)\end{array}$ & $\begin{array}{c}\text { Italy } \\
(n=100)\end{array}$ & $\begin{array}{c}\text { Germany } \\
(n=80)\end{array}$ & $\begin{array}{l}\text { Poland } \\
(n=45)\end{array}$ & $\begin{array}{c}\text { Portugal } \\
(n=60)\end{array}$ & $\begin{array}{l}\text { Russia } \\
(n=85)\end{array}$ & $\begin{array}{c}\text { Spain } \\
(n=200)\end{array}$ & $P$ value & $\begin{array}{c}\text { Total } \\
(n=600)\end{array}$ \\
\hline \multicolumn{10}{|l|}{ Socio-demographics } \\
\hline Age, mean (SD), years & $43.1(8.9)$ & $43.4(9.8)$ & $40.4(13.7)$ & $40.2(11.2)$ & $43.2(13.8)$ & $41.1(10.1)$ & $43.0(12.5)$ & $0.150^{\dagger}$ & $42.6(11.8)$ \\
\hline Female, n (\%) & $25(83.3)$ & $86(86.0)$ & $62(77.5)$ & $37(82.2)$ & $56(93.3)$ & $76(89.4)$ & $173(86.5)$ & $0.177^{\ddagger}$ & $515(85.4)$ \\
\hline \multicolumn{10}{|l|}{ Comorbidities } \\
\hline Anxiety and/or depression, $n(\%)$ & $13(43.3)$ & $40(40.0)$ & $24(30.0)$ & $13(28.9)$ & $46(76.7)$ & $48(56.5)$ & $84(42.0)$ & $<0.0001^{*}$ & $268(44.7)$ \\
\hline Overweight (BMI $\geq 25)$, n (\%) & $5(16.7)$ & $25(25.0)$ & $23(28.7)$ & $1(2.2)$ & $24(40.0)$ & $2(2.4)$ & $31(15.5)$ & $<\mathbf{0 . 0 0 0 1}^{*}$ & $111(18.5)$ \\
\hline Hypertension, n (\%) & $0(0.0)$ & $22(22.0)$ & $18(22.5)$ & $9(20.0)$ & $8(13.3)$ & $10(11.8)$ & $14(7.0)$ & $<0.0001^{*}$ & $81(13.5)$ \\
\hline Gastritis, n (\%) & $6(20.0)$ & $1(1.0)$ & $11(13.8)$ & $7(15.6)$ & $6(10.0)$ & $10(11.8)$ & $21(10.5)$ & $0.003^{\ddagger}$ & $62(10.3)$ \\
\hline Asthma, n (\%) & $2(6.7)$ & $1(1.0)$ & $16(20.0)$ & $0(0.0)$ & $10(16.7)$ & $3(3.5)$ & $19(9.5)$ & $<0.0001^{*}$ & $51(8.5)$ \\
\hline Nephrolithiasis, n (\%) & $1(3.3)$ & $0(0.0)$ & $0(0.0)$ & $1(2.2)$ & $1(1.7)$ & $1(1.2)$ & $30(15.0)$ & $<0.0001^{\ddagger}$ & $34(5.7)$ \\
\hline Syncope, n (\%) & $2(6.7)$ & $0(0.0)$ & $4(5.0)$ & $1(2.2)$ & $4(6.7)$ & $2(2.4)$ & $8(4.0)$ & $0.132^{\ddagger}$ & $21(3.5)$ \\
\hline Ischemia, n (\%) & $0(0.0)$ & $0(0.0)$ & $2(2.5)$ & $0(0.0)$ & $0(0.0)$ & $2(2.4)$ & $1(0.5)$ & $0.307^{\ddagger}$ & $5(0.8)$ \\
\hline \multicolumn{10}{|l|}{ Migraine characteristics } \\
\hline CM diagnosis, n (\%) & $25(83.3)$ & $74(74.0)$ & $44(55.0)$ & $31(68.9)$ & $26(43.3)$ & $54(63.5)$ & $127(63.5)$ & $0.001^{*}$ & $381(63.5)$ \\
\hline Aura, n (\%) & $8(26.7)$ & $25(25.0)$ & $24(30.0)$ & $14(31.1)$ & $17(28.3)$ & $6(7.1)$ & $59(29.5)$ & $0.005^{*}$ & $154(25.5)$ \\
\hline Headache frequency, mean (SD), d/mo & $20.4(9.1)$ & $19.9(8.9)$ & $16.8(8.2)$ & $19.1(9.2)$ & $14.2(4.2)$ & $17.4(9.5)$ & $16.7(8.4)$ & $<0.0001^{\dagger}$ & $17.5(8.5)$ \\
\hline \multicolumn{10}{|l|}{ Medical referral } \\
\hline General practitioner, $\mathbf{n}(\%)$ & $26(86.7)$ & $100(100.0)$ & $23(28.7)$ & 5 (11.1) & $9(15.0)$ & $1(1.2)$ & $11(5.5)$ & $<0.0001^{\ddagger}$ & $175(29.2)$ \\
\hline General neurologist, n (\%) & $3(10.0)$ & $0(0.0)$ & $56(70.0)$ & $5(11.1)$ & $13(21.7)$ & $33(38.3)$ & $123(61.5)$ & $<0.0001^{*}$ & $233(38.8)$ \\
\hline
\end{tabular}

Bold font in the $P$ values column indicates statistically significant.

†Significance assessed with chi-square test.

\#Significance assessed with the one-way ANOVA.

$S D$ standard deviation; $C M$ chronic migraine; $d / m o$ days per month. 
Table 2 General use (\%) of acute treatment according to each country

\begin{tabular}{|c|c|c|c|c|c|c|c|c|c|}
\hline & $\begin{array}{c}\text { Australia } \\
(n=30)\end{array}$ & $\begin{array}{c}\text { Italy } \\
(n=100)\end{array}$ & $\begin{array}{c}\text { Germany } \\
(\mathrm{n}=80)\end{array}$ & $\begin{array}{l}\text { Poland } \\
(n=45)\end{array}$ & $\begin{array}{c}\text { Portugal } \\
(n=60)\end{array}$ & $\begin{array}{l}\text { Russia } \\
(\mathrm{n}=85)\end{array}$ & $\begin{array}{c}\text { Spain } \\
(n=200)\end{array}$ & $P$ value $^{\dagger}$ & $\begin{array}{c}\text { Total } \\
(n=600)\end{array}$ \\
\hline Triptans, n (\%) & $17(56.7)$ & $51(51.0)$ & $57(71.3)$ & $43(95.6)$ & $42(70.0)$ & $72(84.7)$ & $140(70.0)$ & $<0.0001$ & $422(70.3)$ \\
\hline Sumatriptan, n (\%) & $7(23.3)$ & $3(3.0)$ & $28(35.0)$ & $43(93.3)$ & $4(6.7)$ & $64(75.3)$ & $28(14.0)$ & $<0.0001$ & $176(29.3)$ \\
\hline Zolmitriptan, n (\%) & $1(3.3)$ & $2(2.0)$ & $20(25.0)$ & $25(55.6)$ & $20(33.3)$ & $7(8.2)$ & $33(16.5)$ & $<0.0001$ & $108(18.0)$ \\
\hline Rizatriptan, n (\%) & $5(16.7)$ & $9(9.0)$ & $26(32.5)$ & $1(2.2)$ & $10(16.7)$ & $0(0.0)$ & $41(20.5)$ & $<0.0001$ & $92(15.3)$ \\
\hline Eletriptan, n (\%) & $4(13.3)$ & $6(6.0)$ & $6(7.5)$ & $4(8.9)$ & 7 (11.7) & $28(32.9)$ & $32(16.0)$ & 0.001 & 87 (14.5) \\
\hline Almotriptan, n (\%) & $0(0.0)$ & $28(28.0)$ & $5(6.3)$ & $14(31.1)$ & $0(0.0)$ & $0(0.0)$ & $33(16.5)$ & $<0.0001$ & $80(13.3)$ \\
\hline Frovatriptan, n (\%) & $0(0.0)$ & $5(5.0)$ & $9(11.3)$ & $3(6.7)$ & $3(5.0)$ & $0(0.0)$ & $7(3.5)$ & 0.021 & $27(4.5)$ \\
\hline Naratriptan, n (\%) & $1(3.3)$ & $0(0.0)$ & $14(17.5)$ & $0(0.0)$ & $2(3.3)$ & $0(0.0)$ & $2(1.0)$ & 0.008 & $19(3.2)$ \\
\hline NSAIDs, n (\%) & $10(33.3)$ & $84(84.0)$ & 49 (61.3) & $42(93.3)$ & $29(48.3)$ & $44(51.8)$ & $122(61.0)$ & $<0.0001$ & $380(63.3)$ \\
\hline Paracetamol, n (\%) & $15(50.0)$ & $1(1.0)$ & $12(15.0)$ & $29(64.4)$ & 19 (31.7) & $0(0.0)$ & $36(18.0)$ & $<0.0001$ & $112(18.7)$ \\
\hline Combined treatments, n (\%) & $5(16.7)$ & $2(2.0)$ & $30(37.5)$ & $17(37.8)$ & $6(10.0)$ & $22(25.9)$ & $30(15.0)$ & $<0.0001$ & $112(18.7)$ \\
\hline Metamizole, n (\%) & $0(0.0)$ & $0(0.0)$ & $30(37.5)$ & $6(13.3)$ & $12(20.0)$ & $1(1.2)$ & $23(11.5)$ & $<0.0001$ & $72(12.0)$ \\
\hline Opioids, n (\%) & $8(26.7)$ & $0(0.0)$ & $0(0.0)$ & $13(28.9)$ & $3(5.0)$ & $1(1.2)$ & $14(7.0)$ & $<0.0001$ & $39(6.5)$ \\
\hline
\end{tabular}

Bold font in the $\mathrm{P}$ values column indicates statistically significant. tSignificance assessed with chi-square test or Fisher's exact test. NSAIDs non-steroidal anti-inflammatory drug

the same comparative analysis in CM patients, and thus, homogenized the sample. Once again, triptans $(74.0 \%$, $282 / 381)$ and NSAIDs $(66.7 \%, 254 / 381)$ were the most common treatments. Moreover, the same statistically significant differences were observed between countries: while triptans were predominately used in Poland (93.5\%), Russia (84.6\%) and Portugal (74.0\%), NSAIDs were also more frequently used in Poland $(96.8 \%)$ and Italy $(87.8 \%)$. Regarding medical referral, if we only selected patients referred by general neurologists $(38.8 \%$, $233 / 600)$ : triptans $(73.4 \%, 171 / 233)$ and NSAIDS (53.6\%, $125 / 233$ ) were also the standard treatments and nonstatistically significant differences were found in triptan prescription between countries (AU: $66.7 \%$, IT: $79.5 \%$, DE: $62.5 \%$, PL: $80.0 \%$, PT: $76.9 \%$, RUS: $84.8 \%$, ES: $74.0 \% ; p=0.178$ ). However, when we focus the analysis on patients referred by general practitioners $(175 / 600$, $29.2 \%$ ), differences are observed between countries, both in the use of triptans (AU: $53.8 \%$, IT: $51.0 \%$, DE: $91.3 \%$, PL: $80.0 \%$, PT: $55.6 \%$, RUS: $100.0 \%$, ES: $36.4 \% ; p=0.012$ ) and NSAIDs (AU: $34.6 \%$, IT: $84.0 \%$, DE: $73.9 \%$, PL: $100.0 \%$, PT: $55.6 \%$, RUS: $0.0 \%$, ES: $63.6 \%$; $p<0.0001$ ).

\section{Use of preventive migraine medication: pharmacological classes}

In this section, we have analyzed the most used treatments considering those that the patient was currently taking as well those that had been prescribed in the past.

If we evaluate all the patients as a whole, the order of use would be as follows: antidepressants $(69.3 \%, 416 /$ $600)$, AEDs $(54.7 \%, 328 / 600)$, beta-blockers and antihypertensive drugs $(49.7 \%, 298 / 600)$, BTX-A $(44.0 \%$, 264/ $600)$ and others $(36.2 \%, 217 / 600)$. Statistically significant differences were found between all pharmacological classes and countries (Fig. 1): antidepressants were commonly used in all countries, with the exception of Poland; AEDs were more frequently prescribed in
Portugal, Australia and Spain; beta-blockers and antihypertensive drugs were frequently used in all countries except Italy; BTX-A were predominately used in Spain, Italy and Australia and the group of "others" were mainly used in Poland.

Since the selection of the best preventive treatment according to their pharmacological class mainly depends on patient comorbidities, we repeated the same analysis in patients without comorbidities (33.3\%; 200/600) (Fig. 2): antidepressants were most frequently prescribed in Australia, Spain, Italy and Portugal; AEDs were more popular in Australia, Spain and Portugal; beta-blockers and antihypertensive drugs were scarcely used in Italy and Poland; BTX-A was more habitual used in Australia, Spain and Italy and "others" were predominately used in Poland.

\section{Use of migraine preventive medication: antidepressants}

We specifically analyzed antidepressants (AMT, SSRI, SNRI, vortioxetine, opipramol and agomelatine). The most commonly used medications in this pharmacological category were AMT $(54.8 \%, 329 / 600)$, SSRI $(30.0 \%, 180 / 600)$ and SNRI $(14.2 \%, 85 / 600)$. The rest of medications (vortioxetine, opipramol, agomelatine) were only used in $5.2 \%(31 / 600)$ of participants.

Statistically significant differences were found in the prescription of these medications between countries (Fig. 3 a): AMT was more frequently used in Spain, Portugal and Australia; SSRIs were more popular in Portugal, Italy and Russia and SNRIs were predominately used in Russia and Spain. The rest are hardly used: vortioxetine (AU: $0.0 \%$, IT: $2.0 \%$, DE: $0.0 \%$, PL: $0.0 \%$, PT: $1.7 \%$, RUS: $8.2 \%$, ES: $1.0 \%$; $p=0.014$ ); Opipramol only in Germany and Poland (AU: $0.0 \%$ IT: $0.0 \%$, DE: $11.3 \%$, PL: $2.2 \%$, PT: $0.0 \%$, RUS: $0.0 \%$, ES: $0.0 \% ; p<0.0001)$ and agomelatine in Portugal, Russia and Germany (AU: $0.0 \%$, IT: $0.0 \%$, DE: $3.8 \%$, PL: $0.0 \%$, PT: $8.3 \%$, RUS: $1.2 \%$, ES: $0.0 \% ; p=0.001$ ). 


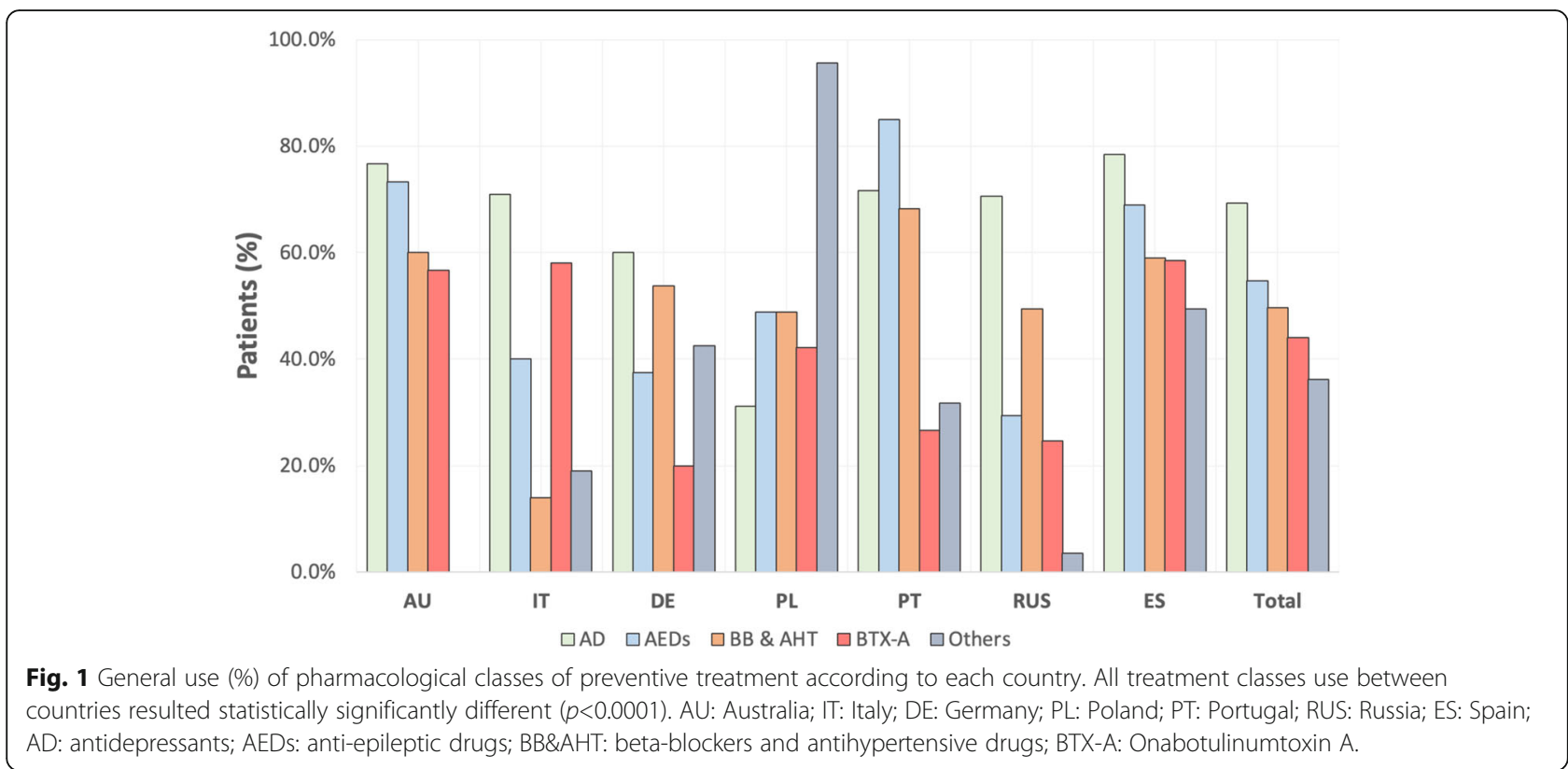

We found that patients included presented differences in the percentage of anxiety-depression as a comorbidity depending on the country. Hence, we analyzed whether countries prescribed differently these treatments in these patients $(44.7 \%, 268 / 600)$. Once again, the most frequently used treatments were AMT $(61.9 \%, 166 / 268)$, SSRI $(58.2 \%, 156 / 268)$ and SNRI $(19.4 \%, 52 / 268)$. Patients with comorbid anxiety and/or depression were treated differently according to their home country: AMT is mostly used in Spain, Germany and Portugal
(AU: $53.8 \%$, IT: $40.0 \%$, DE: $79.2 \%$, PL: $30.8 \%$, PT: 69.6\%, RUS: $43.8 \%$ and ES: $79.8 \%$; $p<0.0001)$; SSRIs were predominately used in Italy (AU: $23.1 \%$, IT: $92.5 \%$, DE: $45.8 \%$, PL: $61.5 \%$, PT: $63.0 \%$, RUS: $60.4 \%$ and ES: $46.4 \% ; p<0.0001)$ and SNRIs were scarcely used in Germany, Portugal and Italy (AU: $23.1 \%$, IT: $2.5 \%$, DE: $0.0 \%$, PL: $30.8 \%$, PT: $0.0 \%$, RUS: $6.7 \%$ and ES: $9.7 \%$; $p<0.0001)$.

Finally, we studied the prescription of antidepressants in patients without comorbidities (Fig. 4 a)

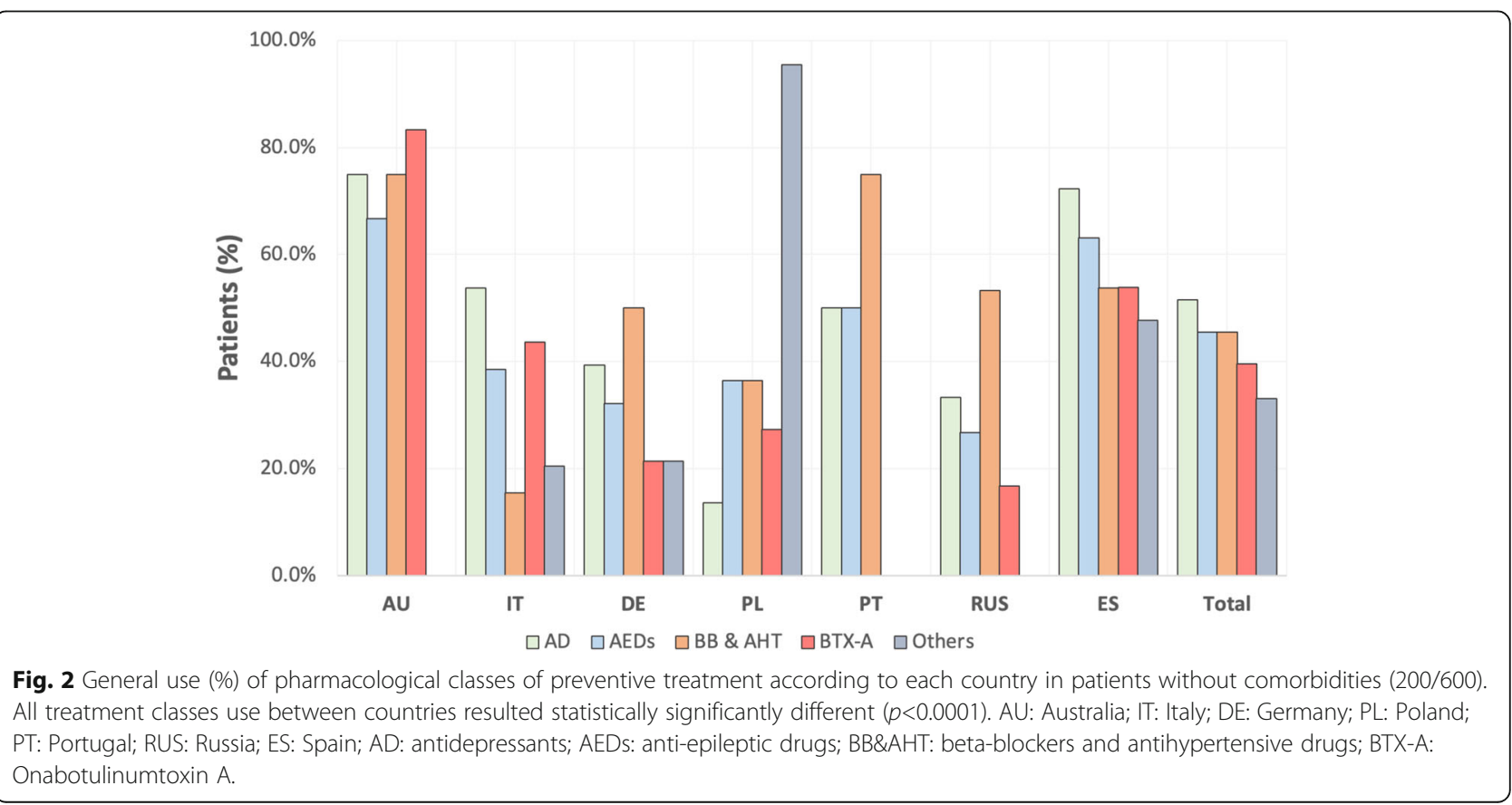




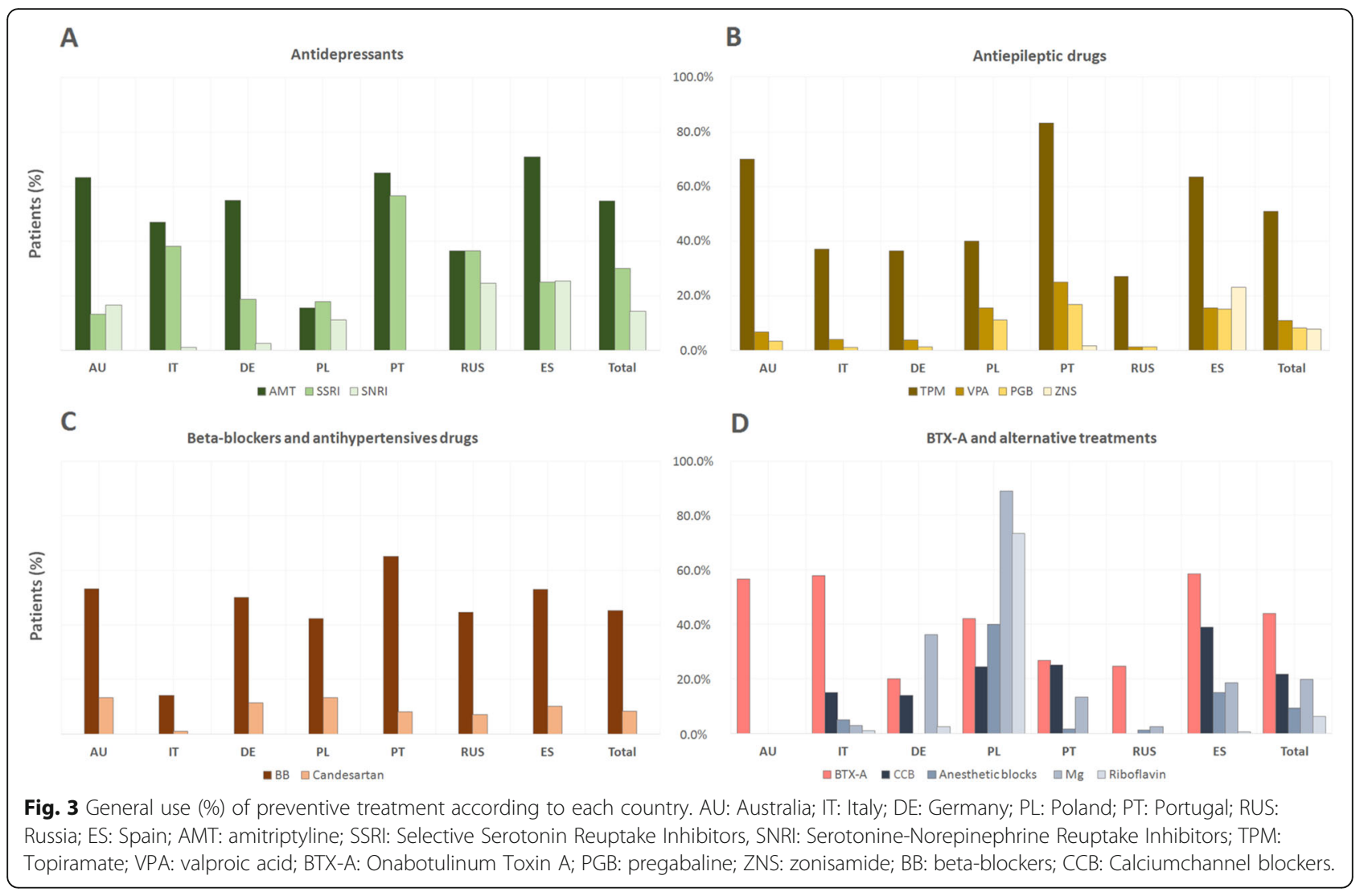

between different countries: AMT was the main medication used and their prescription remained statistically significantly different between countries.

\section{Use of migraine preventive medication: antiepileptic drugs (AEDs)}

In this section, we particularly analyzed the different neuromodulator treatments. The most widely use neuromodulator treatment used was TPM (50.8\%, $305 / 600)$ followed by VPA (10.8\%, 65/600), PGB $(8.2 \%, 49 / 600)$, ZNS $(7.8 \%, 47 / 600)$ and LMT $(2.8 \%$, $17 / 600)$. Statistically significant differences between AEDs used were also found between countries (Fig. 3 b): TPM was predominately used in Portugal, Australia and Spain; VPA and PGB were more popular in Portugal, Spain and Poland and ZNS was practically only used in Spain. No statistically significant differences were found in the use of LMT between countries.

Finally, we studied the prescription of AEDs between countries in patients without comorbidities (Fig. 4 b): TPM was the main medication used and their prescription remained statistically significantly different between countries.
Use of migraine preventive medication: beta-blockers and antihypertensive drugs

Here we studied the distinctive use of $\mathrm{BB}$, candesartan and lisinopril in different countries. In this pharmacological subgroup (Fig. 3 c), BBs were the most popular treatment $(45.3 \%, 272 / 600)$ followed by candesartan $(8.5 \%, 51 / 600)$ and lisinopril $(2.7 \%, 16 / 600)$. BBs and candesartan were commonly used in all countries, with the exception of Italy. Lisinopril was hardly used except in Spain (AU: $0.0 \%$, IT: $0.0 \%$, DE: $1.3 \%$, PL: $0.0 \%$, PT: $0.0 \%$, RUS: $0.0 \%$, ES: $7.5 \%$; $p<0.0001)$.

The prescription of beta-blockers and antihypertensive drugs may vary in patients with cardiovascular risk. In our study, we wanted to analyse the differential use of this pharmacological subgroup in patients with overweight, hypertension and/or cardiac ischemia $(26.3 \%, 158 / 600)$ between countries. In this subgroup, most frequently treatments were also BBs $(51.3 \%, 81 / 158)$ and candesartan $(13.9 \%, 22 / 158)$. While no differences were found in candesartan prescription between countries $(p=0.113)$, the similar statistically significant use was found with BBs (AU: $40.0 \%$, IT: $13.9 \%$, DE: $65.5 \%$, PL: $60.0 \%$, PT: $65.4 \%$, RUS: $63.6 \%$ and ES: $61.0 \% ; p<0.0001)$.

Finally, the prescription of BBs in patients without comorbidities was also statistically significantly different 


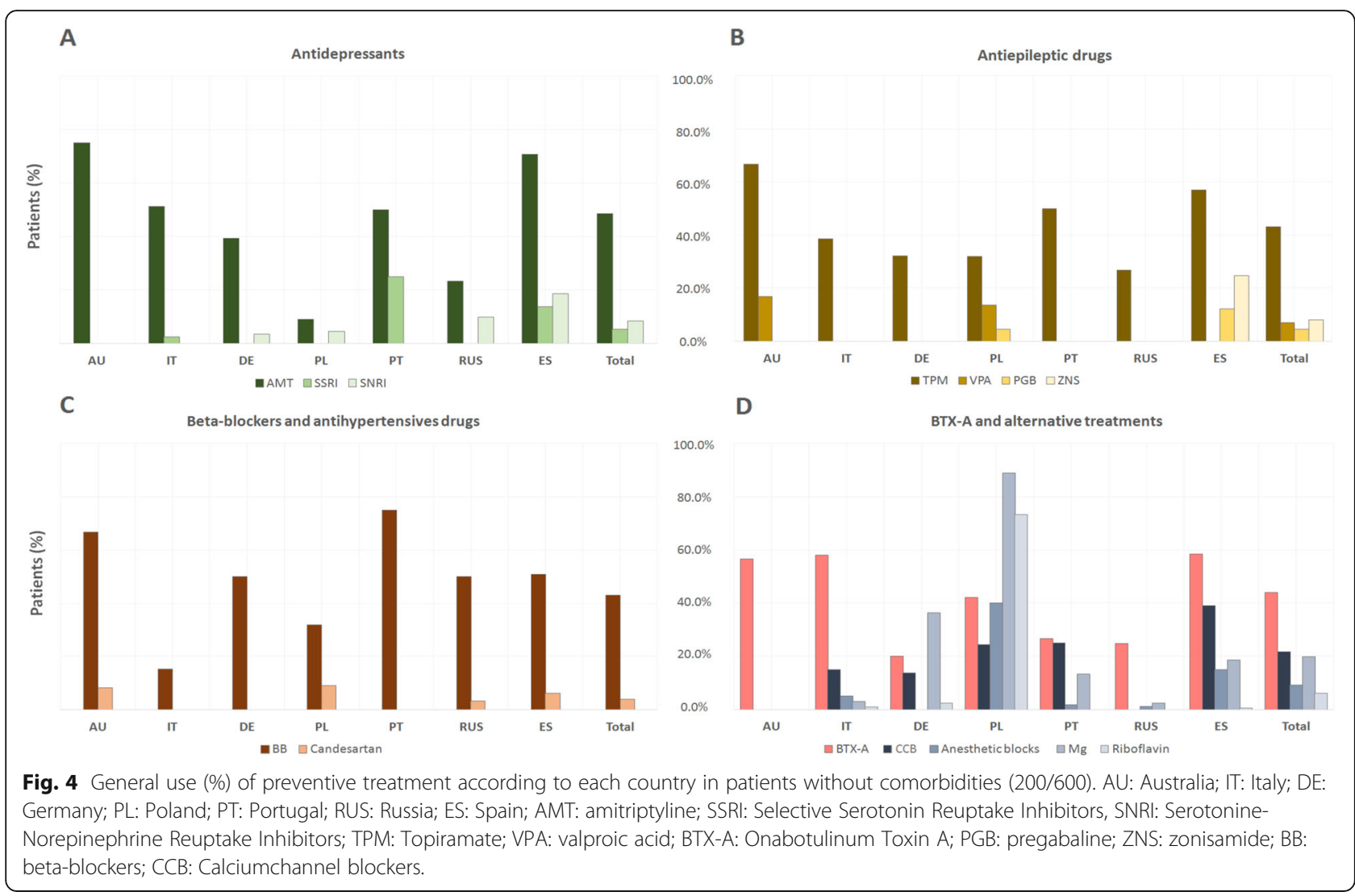

between countries (Fig. 4 c). No differences were found in the use of candesartan and lisinopril between countries in this subset of patients.

Use of migraine preventive medication: other treatments In this group, the most commonly used treatments were CCB (21.7\%, 130/600) followed by $\operatorname{Mg}$ (19.8\%, 119/ $600)$, anaesthetic blocks $(9.2 \%, 55 / 600)$ and riboflavin $(6.2 \%, 37 / 600)$. In relation to other countries (Fig. $3 \mathrm{~d}$ ), CCB has a statistically significant higher use in Spain but $\mathrm{Mg}$, anaesthetic blocks and riboflavin were predominately used in Poland.

The same proportional use between countries was observed in patients without comorbidities (Fig. $4 \mathrm{~d}$ ).

\section{Migraine treatment use according to patient comorbidity}

Statistically significant differences were found in the global set of all patients in the use of preventive treatments considering the patient's previous pathology. Thus, we finally studied the differential prescription of pharmacological subgroups and the presence/absence of frequent comorbidities in our cohort (presence $\geq 10 \%$ ). In this context, patients with presence of anxiety and/or depression were statistically significantly more frequently prescribed with antidepressants (absence: 53.3\% vs. presence: $89.2 \%$; $p<0.0001$ ), AEDs (absence: $49.1 \%$ vs. presence: $61.6 \% ; p=0.002$ ) and BTX-A (absence: $38.3 \%$ vs. presence: $51.1 \% ; p=0.003$ ). Popular pharmacological categories in overweight patients were antidepressants (absence: $67.5 \%$ vs. presence: $77.5 \%$; $\mathrm{p}=0.041$ ) and AEDs (absence: $52.1 \%$ vs. presence: $65.8 \%$; $p=0.011$ ). Specifically, the use of TPM is higher $60.4 \%(67 / 111$ subgroup of overweight patients) vs. $50.8 \%(305 / 600$ total sample) and the use of CCB is slightly lower $20.7 \%$ $(23 / 111)$ vs. $21 \%(130 / 600)$, and this is even less if both comorbidities are present, being overweight and experiencing mood alteration (16.1\% (9/56) vs. $21 \%)$. Surprisingly, the use of VPA in overweight patients is slightly higher $11.7 \%$ (13/111) vs. $10.8 \%$ (65/600). Regarding hypertension, patients were more commonly treated with beta-blockers/antihypertensive drugs (absence: $47.6 \%$ vs. presence: $63.0 \% ; p=0.012$ ) and BTX-A (absence: $42.2 \%$ vs. presence: $55.6 \% ; p=0.030)$. The use of $\mathrm{BB}$ was lower in patients with asthma (absence: 46.1 vs. presence: $37.3 \% p=0.243)$. Finally, patients with gastritis were more commonly prescribed alternative treatments (absence: $34.8 \%$ vs. presence: $48.4 \% ; p=0.037$ ).

\section{Discussion}

There are multiple reviews on the best preventive treatments for patients with migraine [7-11], as well as European and American recommendations [3, 4, 12] and 
national guidelines in each country $[5,6,13,14]$, however there is no consensus on which the drug of first choice is, due to the limitations of comparative studies carried out to date, with few head to head comparisons $[15,16]$, where there is only one study which also includes non-oral treatments [17].

This is the first international multicentre study with the aim of comparing whether there are differences in the use of acute and preventive migraine treatments when analyzing the drugs prescribed in seven countries.

It can be seen that there is no single first-line drug of choice as preventive treatment, and significant differences can be observed between countries and there is a wide arsenal of drugs used, opting for one or the other according to the patient's profile and their comorbidities, but there are also differences in relation to the nationality of the prescribing physician.

In our study, we have analyzed a total of 734 patients from seven different countries (Australia, Italy, Germany, Poland, Portugal, Russia and Spain), from specialized headache units, which implies a more complex patient profile, often with a long pharmacological history. The mean number of days of pain per month was almost 20, with a high percentage of drugs tested by each patient, over all in Spain, Portugal and Poland.

In relation to acute treatment, given the patient's profile and being monitored in a specialized unit, it is not surprising to find that the percentage of use of triptans is generally high in all countries. Sumatriptan is the most widely used of these, possibly because it has the longest therapeutic course and naratriptan and frovatriptan was the least used, perhaps because these are usually considered to be more tolerable but a bit slower and with longer half-lives [18]. However, there are also differences between countries; sumatriptan is used much more in countries like Poland (93.3\%) or Russia (75.3\%) compared to others such as Italy, which only accounts for $3 \%$ or Portugal $6.4 \%$. Nevertheless, when we separate this aspect in relation to the referring physician, it becomes clear that this difference is possibly due more to whether the patient had been referred by primary care or general neurology, than actually to nationality. NSAI Ds are also widely used, in contrast to other analgesics such as paracetamol, metamizole, opioids and combined, in line with international recommendations $[19,20]$.

Regarding migraine preventive treatment, the most commonly used drugs were antidepressants (69.3\%), AEDs (54.7\%) and beta-blockers (49.7\%), in this order. However, at this point we found significant differences between countries.

Firstly, in relation to the use of antidepressants, AMT was used in all countries in more than $1 / 3$ of patients (especially in Spain, Portugal and Australia), except in Poland (16\%). In relation to the other antidepressants, the next ones in use are the SSRIs, especially in countries such as Portugal, Italy or Russia. SNRIs are less used in general, with Russia and Spain as exceptions. AMT was also the most used drug, both in the subgroup of patients with anxiety and/or depression, whereas in countries like Portugal it represents a very high percentage, and in the subgroup without comorbidities.

Secondly, the most widely used neuromodulator treatment was TPM, also in patients without comorbidities, however countries like Russia use it significantly less, approximately in $1 / 4$ patients, compared to others such as Portugal or Australia, where it has been prescribed in 3/ 4 or Spain in $2 / 3$. In a much smaller percentage, VPA and PGB were more popular in Portugal, Spain and Poland.

$\mathrm{BB}$ were the most used preventive treatment within the group of antihypertensives. $\mathrm{BB}$ and candesartan were commonly prescribed in all countries, with the exception of Italy.

BTX-A, a first-line drug together with TPM in chronic migraine [21], is widely used, also considering that they are patients in specialized units, especially in Spain, Italy and Australia.

In relation to anaesthetic blocks, their use is much less common, except in Poland (40\%), where the use of nutraceuticals also predominates. Here, almost all patients have tried Riboflavine or $\mathrm{Mg}$ (the latter is used more by the rest of the countries except for Australia, Italy and Russia).

In the use of $\mathrm{CCB}$, important differences appear, such as its use in Spain of almost $40 \%$ vs. in countries such as Australia or Russia, where no prescriptions were made.

Drugs like pregabalin, LMT, vortioxetine, agomelatine are hardly used. There are drugs such as ZNS and lisinopril, which were prescribed almost exclusively in Spain or Opipramol in Germany. Possibly due to low scientific evidence $[22,23]$ except in the case of lisinopril [24].

The findings in relation to the use of preventive treatments and patient comorbidity are consistent with our usual clinical practice. Therefore, in those patients with previous cardiac ischemia or who have hypertension, $\mathrm{BB}$ or antihypertensives such as candesartan for their dual effect are commonly used; and, we avoid them in patients with asthma in the case of non-selective BB [25]. Another key point, looking for synergistic effects is also mood comorbidity. In these patients we use drugs with double effect, such as AMT, SSRI, SNRI or drugs that do not worsen it, such as antihypertensives and we reject CCB [26], which also lead to weight gain. Some do the opposite such as TPM, while others have no effect on weight such as BTX-A and this is also observed in the choice of preventive treatment [27]. 
Nevertheless, when only analyzing patients without comorbidities - in order not to affect the choice of treatment - significant differences persist in all pharmacological groups.

This study presents a number of considerations that must be taken into account. The main limitation of our study is that for each country only one or two centres participated, so it must not be inferred that it is a representation of the global prescribing trends of each country, but rather it is based on the opinion of neurologists of different nationalities. However, in relation to this point, it is important to consider that all participating physicians work in specific headache units and all of them have been trained in line with the guidelines of each country and they follow their national recommendations. It should also be noted that the number of patients included in some countries is low in relation to others, which means that perhaps if the size of patients analyzed were increased, the differences could be greater. We have not divided the uses in episodic or chronic migraine due to the fact that all drugs prescribed to the patient are analyzed, where it is not possible to know whether a drug was prescribed in a period with a lower or higher frequency of attacks. Moreover, in the list of preventive treatments taken by the patient, it was not indicated who had made the prescription and it is possible that some of the first treatments used were not prescribed in the specialized headache centre, rather by the primary care physician or the general neurologist, although these patients usually have an early referral due to their complexity and, likewise, there is an the overall trend in the country. Lastly, with regard to treatment with anti-CGRP monoclonal antibodies, the results are not included because in many of the countries included in the study at the time when this study was carried out, they were not approved by their National Healthcare Service.

\section{Conclusions}

In the process of choosing the most appropriate acute or preventive migraine treatment, comorbidities, the patient's opinion [28], and of course, that of the neurologist must always be assessed, but as we have observed in this first international study, this may differ depending on the country where the treatment is prescribed.

In fact, the European guidelines to dictate the new monoclonal treatments against CGRP [29] indicate that at least two oral treatments must be prescribed (and BTX-A in the case of chronic migraine), however, it is not specified which should be the two first options.

This investigation shows the need for a larger multicentre study to verify these results and to continue with comparative clinical trials between the first line treatments, in order to create global international algorithms that guarantee the best therapeutic option for our patients.

\section{Abbreviations}

AMT: Amitriptyline; AU: Australia; BB: Beta-Blokers; BMI: Body mass index; BTXA: Onabotulinumtoxin A; CCB: calcium channel blockers; CGRP: calcitonin gene related peptide; ES: Spain; DE: Germany; IT: Italy; LMT: Lamotrigine; Mg: Magnesium; PL: Poland; PT: Portugal; PGB: Pregabalin; RUS: Russia; SNRI: Serotonin and Norepinephrine reuptake inhibitors; SSRI: Serotonin reuptake inhibitors; TPM: Topiramate; VPA: Valproic acid; ZNS: Zonisamide

\section{Acknowledgements}

AbbVie-Allergan supported the publication fees.

\section{Authors' contributions}

AGV, JH, NL and PPR participated in the design of the study. AGV, JH, NL, AVC, MTF, AAR, SS, IF, RO, RR, IM, AG and CS collaborated in the data collection. AGV and VJG contributed to analysis and interpretation of data. AGV wrote first draft. All the author critically revised the final draft and approved the final manuscript.

\section{Funding}

This work did not receive any funds.

\section{Availability of data and materials}

Study material and supplementary material are available upon request to the corresponding author

\section{Declarations}

\section{Ethics approval and consent to participate}

This study was approved by Hospital de la Princesa's Ethics Committee (register number: 3477). Patient data were anonymised for data analysis.

\section{Consent for publication}

All authors gave their consent for publication.

\section{Competing interests}

Gago-Veiga AB has received honoraria as a consultant and speaker for: AbbVie-Allergan, Chiesi, Exeltis, Novartis, Eli Lilly and Teva.

Huhn J-I has received honaria as speaker or travel grants for: AbbVieAllergan, Novartis, Teva, Eli-Lilly and md-hoizonte.

Latysheva $\mathrm{N}$ has received honoraria as a consultant and speaker for: AbbVieAllergan and Novartis.

Torres-Ferrus $\mathrm{M}$ has received honoraria as consultant or speaker for AllerganAbbvie, Almirall, Chiesi, Eli Lilly, Novartis and Teva.

Alpuente A has received honoraria as speaker for Allergan-Abbvie, Eli Lilly and eductation for Chiesi, Novartis and Teva.

Sacco $S$ has received honoraria as a consultant and speaker for: Abbot,

Allergan-Abbvie, AstraZeneca, Eli Lilly, Novartis and Teva. Her research group has received research grants from Allergan-Abbvie and Novartis and has received funding for clinical trials from Allergan-Abbvie, Novartis and Teva. She is a member of the Council of the European Headache Society and co-chair of the guideline board of the European Stroke Organization. She is the Specialty Chief Editor in Headache Medicine and Facial Pain in Frontiers in Neurology, associate editor for The Journal of Headache and Pain and for Stroke in Frontiers in Neurology, assistant editor for Stroke and member of the editorial board of Neurological Sciences, International Journal of Stroke, European Stroke Journal.

Ornello R has received personal fees from Novartis and Ei Lilly, funding for publication fees from Allergan and Novartis, and travel grants from Novartis and Teva.

Ruscheweyh $\mathrm{R}$ has received honoraria for talks and/or advisory boards from Allergan, Hormosan, Lilly, Novartis and Teva.

Marques IB has received honoraria as speaker and/or advisory board for: AbbVie-Allergan, Sanofi and Novartis.

Gryglas-Dworak A. has received honoraria as a consultant or speaker for AbbVie-Allergan and Novartis.

Pozo-Rosich P has received honoraria as a consultant and speaker for: Allergan-Abbvie, Almirall, Amgen, Biohaven, Chiesi, Eli Lilly, Medscape, Neurodiem, Novartis and Teva. Her research group has received research grants from Allergan, and has received funding for clinical trials from Alder, Allergan-Abbvie, Electrocore, Eli Lilly, Novartis and Teva. She is a trustee member of the board of the International Headache Society, member of the 
Council of the European Headache Society. She is in the editorial board of Revista de Neurologia, associate editor for Cephalalgia, Headache, Neurologia, Frontiers of Neurology and The Journal of Headache and Pain. She is a member of the Clinical Trials Guidelines Committee of the International Headache Society. She has edited the Guidelines for the Diagnosis and Treatment of Headache of the Spanish Neurological Society. She is the founder of www.midolordecabeza.org. Pozo-Rosich P does not own stocks from any pharmaceutical company.

Vieira-Campos A, Frattale I, Stark C and Gallardo VJ report no disclosures

\section{Author details}

${ }^{1}$ Headache Unit, Department of Neurology, La Princesa Research Institute. Hospital Universitario de la Princesa, Madrid, Spain. ${ }^{2}$ Praxis Gendolla. Zentrum für Neurologie und Schmerztherapie, Essen, Germany. ${ }^{3}$ Department of Neurology, Institute for Professional Education, I.M.Sechenov First Moscow State Medical University (Sechenov University), Moscow, Russia. ${ }^{4}$ Headache Unit, Neurology Department, Hospital Universitari Vall d'Hebron, Barcelona, Spain. ${ }^{5}$ Headache and Neurological Pain Research Group, Vall d'Hebron Research Institute, Departament de Medicina, Universitat Autònoma de Barcelona, Barcelona, Spain. ${ }^{6}$ Neuroscience Section, Department of Applied Clinical Sciences and Biotechnology, University of L'Aquila, L'Aquila, Italy. ${ }^{7}$ Department of Neurology, Ludwig Maximilians University Munich, Munich, Germany. ${ }^{8}$ Department of Neurology, Hospital da Luz Lisboa, Lisbon, Portugal. ${ }^{9}$ Private Headache Clinic, Wroclaw, Poland. ${ }^{10}$ Austin Health, Heidelberg, Australia.

Received: 4 February 2021 Accepted: 12 May 2021

Published online: 24 May 2021

\section{References}

1. Steiner TJ, Stovner $L$, Jensen $R$ et al (2020) Migraine remains second among the worlds-s causes of disability, and first among young women: findings from GBD2019. J Headache Pain 21:137

2. Lipton RB, Bigal ME, Diamond M, Freitag F, Reed ML, Stewart WF, AMPP Advisory Group (2007) Migraine prevalence, disease burden, and the need for preventive therapy. Neurology 68:343-349

3. Loder E, Burch R, Rizzoli P (2012) The 2012 AHS/AAN guidelines for prevention of episodic migraine: a summary and comparison with other recent clinical practice guidelines. Headache 52:930-945

4. Evers S, Afra J, Frese A (2009) EFNS guideline on the drug treatment of migraine - revised report of an EFNS task force. Eur J Neurol 16:968-981

5. Diener H-C, Holle-Lee D, Nägel S et al. Treatment of migraine attacks and prevention of migraine: Guidelines by the German Migraine and Headache Society and the German Society of Neurology. Clinical and Translational Neuroscience. 2019

6. Ezpeleta d, Pozo-Rosich P. Guías diagnósticas y terapéuticas de la Sociedad Española de Neurología. Guía oficial de práctica clínica en Cefaleas. Ed. Luzán 5, Madrid. 2015

7. Headache Classification Committee of the International Headache Society (HIS). The International Classification of Headache Disorders, 3rd edition. Cephalalgia 2018; 38: 1-211

8. Parikh Sk, Silverstein SD (2019) Preventive treatment for episodic migraine. Neurol Clin 37:753-770

9. Schwedt TJ (2018) Preventive therapy of migraine. Continuum 24:10521065

10. Rizzoli P (2014) Preventive pharmacotherapy in migraine. Headache 54:364369

11. Lipton R, Silberstein S (2015) Episodic and chronic migraine headache: Episodic and chronic migraine headache: breaking down barriers to optimal treatment and prevention. Headache 55:103-122

12. The American Headache Society (2019) Position Statement on Integrating new migraine treatments into clinical practice. Headache 59:1-18

13. Sarchielli P, Granella F, Prudenzano MP, Pini LA, Guidetti V, Bono G, Pinessi L, Alessandri M, Antonaci F, Fanciullacci M, Ferrari A, Guazzelli M, Nappi G, Sances G, Sandrini G, Savi L, Tassorelli C, Zanchin G. Italian guidelines for primary headaches: 2012 revised version. J Headache Pain 2012; Suppl2: S31-70

14. Lantéri-Minet $M$, Demarquay $G$, Alchaar H, Bonnin J, Cornet P, Douay X, Dousset V, Géraud G, Guillouf V, Navez M, Radat F, Radenne S, Revol A, Valade D, Donnet A (2014) Management of chronic daily headache in migraine patients: medication overuse headache and chronic migraine. French guidelines. Rev Neurol (Paris) 170:162-176

15. Jackson J, Cogbill E, Santana-Davila R, Eldredge C, Collier W, Gradall A, Sehgal N, Kuester J (2015) A comparative effectiveness meta-analysis of drugs for prophylaxis of migraine. PloS One 10:e0130733

16. Ashtari F, Shaygannejad V, Akbari M (2008) A double-blind, randomized tria of low-dose topiramate vs propanolol in migraine prophylaxis. Acta Neurol Scand 118:301-305

17. Rothrock JF, Adams AM, Lipton RB, Silberstein SD, Jo E, Zhao X, Blumenfeld AM (2019) FORWARD Study investigative group. FORWARD Study: Evaluating the Comparative Effectiveness of OnabotulinumtoxinA and Topiramate for Headache Prevention in Adults with Chronic Migraine. Headache 59:1700-1713

18. Ferrari MD, Roon Kl, Lipton RB, Goadsby PJ (2001) Oral triptans (serotonin 5HT (1b/1d) agonist) in acute migraine treatment: a meta-analysis of 53 trials. Lancet 358:1668-1675

19. Marmura MJ, Silberstein S, Schwedt T (2015) The acute treatment of migraine in adults: the american headache society evidence assessment of migraine pharmacotherapies. Headache 55:3-20

20. Cameron C, Kelly S, Hsieh SC, Murphy M, Chen L, Kotb A, Peterson J, Coyle D, Skidmore B, Gomes T, Clifford T, Wells G (2015) Triptans in the acute theatment of migraine: A systematic Review and Network Meta-analysis. Headache 55(Suppl4):221-235

21. Aurora SK, Dodick DW, Turkel CC, DeGryse RE, Silberstein SD, Lipton RB, Diener HC, Brin MF (2010) PREEMPT 1 Chronic Migraine Study Group. Cephalalgia 30:793-803

22. Pascual-Gómez J, García-Naya M, Leira R. Mateos V, Alvaro-Gonzalez C, Hernando I (2010) Et al. Zonisamide in the preventive treatment of refractory migraine. Rev Neurol 50:129-132

23. Jacobs H (1972) A trial of opipramol in the treatment of migraine. J Neurol Neurosurg Psychiatry 35:500-504

24. Schrader $H$, Stovner $\amalg$, Helde $G$ et al. Prophylactic treatment of migraine with an angiotensin converting enzyme inhibitor (Lisinopril): randomised, placebo controlled, crossover study. BMJ 322: 19-22

25. Kuipers E, Wensing M, De Smet, Teicher M (2018) Considerations of prescribers and pharmacists for the use of non-selective B-Blockers in asthma and COPD patients. J Eval Clin Pract 24:396-402

26. Lugaresi A, Montagna P, Gallasi R, Lugaresi E. Extrapyramidal syndrome and depression induced by flunarizine. Eur Neurol 188; 28: 208-11

27. Taylor $F$ (2008) Weight change associated with the use of migrainepreventive medications. Clin Ther 30:1069-1080

28. Dekker F, Knuistingh A, Andriesse B, Kernick D, Reis R, Ferrari M et al (2012) Prophylactic treatment of migraine; the patient's view, a qualitative study. BMC Fam Pract 9:13:13

29. Sacco S, Bendtsen L, Ashina M, Reuter U, Terwindt G, Mitsikostas DD, Martelletti P (2019) European headache federation guideline on the use of monoclonal antibodies acting on the calcitonin gene related peptide or its receptor for migraine prevention. J Headache Pain 20:6

\section{Publisher's Note}

Springer Nature remains neutral with regard to jurisdictional claims in published maps and institutional affiliations.

\section{Ready to submit your research? Choose BMC and benefit from:}

- fast, convenient online submission

- thorough peer review by experienced researchers in your field

- rapid publication on acceptance

- support for research data, including large and complex data types

- gold Open Access which fosters wider collaboration and increased citations

- maximum visibility for your research: over $100 \mathrm{M}$ website views per year

At BMC, research is always in progress.

Learn more biomedcentral.com/submissions 